\title{
HOW DO SPORTS AFFECT STATIC BAROPODOMETRY? AN OBSERVATIONAL STUDY AMONG WOMEN LIVING IN SOUTHERN ITALY
}

original paper

( ) University School of Physical Education in Wroclaw

DOI: https://doi.org/10.5114/hm.2019.78091

\section{KALTRINA FEKA ${ }^{1}$, FRANCESCO POMARA ${ }^{2}$, GIUSEPPE RUSSO ${ }^{3}$, MARIA CUSMA PICCIONE ${ }^{2}$, MARCO PETRUCCI ${ }^{2}$, VALERIO GIUSTINO ${ }^{4}$, GIUSEPPE MESSINA ${ }^{4}$, ANGELO IOVANE ${ }^{3}$, ANTONIO PALMA ${ }^{3}$, ANTONINO BIANCO ${ }^{3}$}

\author{
${ }^{1}$ Ph.D. Program in Health Promotion and Cognitive Sciences, University of Palermo, Palermo, Italy \\ ${ }^{2}$ MEDEOR Research Institute, Palermo, Italy \\ ${ }^{3}$ Sport and Exercise Sciences Research Unit, Department of Psychology, Educational Science and Human Movement, \\ University of Palermo, Palermo, Italy \\ ${ }^{4}$ PosturaLab Italia, Palermo, Italy
}

\begin{abstract}
Purpose. The aim of the study was (a) to investigate the differences in plantar pressure distribution between athletes (A) and sedentary (S) women; (b) to examine the differences, if any, in plantar pressure between sports within the A group.

Methods. The study involved 173 females; 98 were S (age: $24.23 \pm 6.11$ years; height: $161.11 \pm 6.44 \mathrm{~cm}$; weight: $56.70 \pm$ $8.19 \mathrm{~kg}$; BMI: $21.81 \pm 2.52 \mathrm{~kg} / \mathrm{m}^{2}$; body surface area [BSA]: $1.59 \pm 0.13$; shoe size: $37.83 \pm 1.53$ ), 75 were A (age: $22.47 \pm 4.89$ years; height: $159.98 \pm 5.95 \mathrm{~cm}$; weight: $55.49 \pm 7.61 \mathrm{~kg}$; BMI: $21.62 \pm 2.18 \mathrm{~kg} / \mathrm{m}^{2}$; BSA: $1.57 \pm 0.12$; shoe size: $38.05 \pm 1.55$ ). For plantar support analysis, the FreeMed posturography system was used, including the FreeMed baropodometric platform and FreeStep v. 1.0.3 software.
\end{abstract}

Results. No significant differences were found between groups regarding anthropometric data, in the total surface, fore-foot, rear-foot, total left or total right foot surface. Significant differences between S and A were observed in fore-foot (S: $50.39 \pm$ 3.60\%; A: $52.36 \pm 3.76 \%)$ and rear-foot load distribution $(p=0.0006 ; p=0.0006)$. Also the maximal peak pressure (S: $518.06 \pm$ $111.50 \mathrm{~g} / \mathrm{cm}^{2}$; A: $445.38 \pm 88.47 \mathrm{~g} / \mathrm{cm}^{2}$ ) and the mean pressure showed significant differences between groups. There were significant differences between sports in total surface and fore-/rear-foot and total left/right surfaces ratios.

Conclusions. Women practising sport differ from sedentary ones in the fore-/rear-foot pressure ratio. In addition, we detected plantar surface and fore-/rear-foot pressure ratio differences within the athletes group.

Key words: sedentary, athlete, baropodometry, plantar pressure distribution

\section{Introduction}

Posture is not a simple matter to investigate, and the perspectives or approaches can vary according to the areas of interest. Previous findings have highlighted how postural measurements with the use of photography or costly devices like magnetic resonance imaging are still scientifically inaccurate, while, on the other hand, the X-ray examination includes radiation problems [1]. In addition, the neurological control of posture and locomotion is co-dependent at different levels of the central nervous system [1-4]. However, to maintain postural control in different environmental situations, these systems must be strongly integrated $[3,4]$. Additionally, the fundamental importance of the foot on upright standing and locomotion has been clearly established [5]. It is the first body part to receive the impact, and serves as a base for support [1]. There are several factors, though, that affect the erect position and some authors have already reported a few

Correspondence address: Antonino Bianco, Sport and Exercise Sciences Research Unit, University of Palermo, Via Giovanni Pascoli 6, 90144, Palermo, Italy, e-mail: antonino.bianco@unipa.it

Received: August 14, 2018

Accepted for publication: August 20, 2018

Citation: Feka K, Pomara F, Russo G, Piccione MC, Petrucci M, Giustino V, Messina G, Iovane A, Palma A, Bianco A. How do sports affect static baropodometry? an observational study among women living in southern Italy. Hum Mov. 2019;20(1):9-16; doi: https://doi.org/10.5114/hm.2019.78091. 
details about them [6]. The human ability to keep balance is influenced by different external and internal elements, such as genetics, the state of the vestibular apparatus, age, the area of support, centre of mass positioning, coordination, strength, flexibility, emotional state, frequency of participation in motor activities and training status [2, 3, 6]. Nevertheless, a complete understanding of foot function during locomotion is important for essential research on normal human behaviour, as well as in clinical situations [7]. Being able to do daily tasks and sports activities is necessary to coordinate body parts with appropriate actions, reactions, and skills [6]. Since, it is known that participating in different sports causes physiological and anthropometric changes in human body and according to several studies, sports participation may result in changing/improving physical fitness, as well as increasing lean body mass, bone mineral content and other body parameters [5]. However, some sports practised at an early age (e.g. gymnastics) can delay the onset of puberty and menarche compared with other school girls or female swimmers [8]. Furthermore, anthropometrics change as a result of the specificity of the sport that is practised $[5,8,9]$.

Different authors suggested that baropodometry was a reliable instrument to determine plantar pressure distribution [1, 10], while Alves et al. [11] reported that baropodometric results should be interpreted with caution in science and in clinical practice. In this regard, Phethean and Nester [12] pointed out the influence of body weight, body mass index (BMI), and gender on plantar pressure distribution. Moreover, plantar pressure refers to the pressure measured on the plantar surface of the foot [13], and, of interest, a proper biomechanics of the foot is responsible for upholding body posture and balanced distribution of plantar pressure [1]. However, changes in plantar pressure distribution are linked to many factors that may significantly interfere with physical training and, consequently, sports performance [14]. Remarkably, Potdevin et al. [15] investigated plantar pressure asymmetry in order to discuss the opportunity to make a diagnose of pathological gait and guide further rehabilitation process. Neto et al. [3] stated that baropodometry allowed an understanding of the physiopathology of postural alterations, while the same analysis was suggested to assess dysfunctions of the feet $[1,16]$. Previous studies have also reported the influence of different sports on plantar static and dynamic load distribution [17-19].

Nowadays, what seems to be clear is that being overweight, obese, active (athletes), or having any kind of health problems affects plantar pressure distribution [16, 20-22]. While the majority of published scientific papers investigated mostly males [23], in our case, the purpose of the study was two-fold: (a) to explore the differences in plantar pressure distribution between athletes and sedentary women; and (b) to investigate the differences, if any, in plantar pressure between sports within the athletes group.

\section{Material and methods}

\section{Subjects}

The total of 173 healthy females participated in the study; 75 of them practised different sports, such as soccer $(n=18)$, rowing $(n=11)$, dancing $(n=12)$, swimming $(n=16)$, and judo $(n=18)$, while 98 did not participate in any sport (they led a sedentary lifestyle). The subjects were divided into 2 groups: 75 athletes, group A; and 98 sedentary women, group $\mathrm{S}$. The anthropometric data of the participants, presented in means, are included in Table 1. All athletes enrolled in the study had practised their specific sports for at least 3 years.

\section{Study design and measurements}

A cross-sectional study was carried out. The same researcher (Francesco Pomara) recorded the shoe size, body weight to the nearest $100 \mathrm{~g}$ using scales (Seca 709, Hamburg, Germany), and body height to the nearest $1 \mathrm{~mm}$ using a wall stadiometer (Seca 220, Hamburg, Germany). Furthermore, mean \pm standard deviation (SD) of BMI (determined as weight in kilograms divided by height in meters squared) and Body Surface Area (BSA) were calculated in both groups. The BSA was obtained through the Mosteller formula [24]. Furthermore, orthopaedic and nervous pathologies

Table 1. Age and physical characteristics of the sedentary (S) and athlete (A) groups

\begin{tabular}{lrrl}
\hline Parameter & \multicolumn{1}{c}{$\mathrm{S}$} & \multicolumn{1}{c}{$\mathrm{A}$} \\
$(n=98)$ & \multicolumn{1}{c}{$(n=75)$} & $p$-value \\
\hline Age (years) & $24.23 \pm 6.11$ & $22.47 \pm 4.89$ & $\mathrm{NS}$ \\
Height $(\mathrm{cm})$ & $161.11 \pm 6.44$ & $159.98 \pm 5.95$ & $\mathrm{NS}$ \\
Body weight $(\mathrm{kg})$ & $56.70 \pm 8.19$ & $55.49 \pm 7.61$ & $\mathrm{NS}$ \\
BMI $\left(\mathrm{kg} / \mathrm{m}^{2}\right)$ & $21.81 \pm 2.52$ & $21.62 \pm 2.18$ & $\mathrm{NS}$ \\
BSA $\left(\mathrm{m}^{2}\right)$ & $1.59 \pm 0.13$ & $1.57 \pm 0.12$ & $\mathrm{NS}$ \\
Shoe size & $37.83 \pm 1.53$ & $38.05 \pm 1.55$ & $\mathrm{NS}$ \\
\hline
\end{tabular}

BMI - body mass index, BSA - body surface area, NS - not significant 
concerning the women's families and personal medical histories of each participant were considered as exclusion criteria. For plantar support, the FreeMed posturography system was used, including the FreeMed baropodometric platform and FreeStep v. 1.0.3 software. The sampling rate was set at $25 \mathrm{~Hz}$. The sensors, coated with $24 \mathrm{~K}$ gold, guarantee the repeatability and reliability of the instrument (produced by Sensor Medica, Guidonia Montecelio, Roma). The participants were asked to maintain the standardized Romberg test position (standing upright with eyes closed) on the baropodometric platform [25]. Each foot was divided into the anterior (fore-foot) and posterior (rear-foot) area, with an approximation to $1 \mathrm{~mm}$.

\section{Statistical analysis}

All data are expressed as mean \pm SD. Differences between the groups were analysed with the use of Student's $t$-test for independent samples. The one-way analysis of variance (ANOVA) with Tukey's multiple comparison post-hoc test was adopted in the case of multiple comparisons. The analysis was performed with the InStat GraphPad Prism 7.0 software (San Diego, CA, USA). The results were considered to be statistically significant at $p<0.05$.

\section{Ethical approval}

The research related to human use has been complied with all the relevant national regulations and institutional policies, has followed the tenets of the Declaration of Helsinki, and has been approved by the Ethics Committee of the University of Palermo.

\section{Informed consent}

Informed consent has been obtained from all individuals included in this study.

\section{Results}

Table 1 provides an overview of the included participants with information referring to age (years), height $(\mathrm{cm})$, body weight $(\mathrm{kg})$, BMI $\left(\mathrm{kg} / \mathrm{m}^{2}\right)$, BSA $\left(\mathrm{m}^{2}\right)$, and shoe size for both the sedentary and athlete group. However, no significant differences were found between the groups.

Table 2 shows plantar surface areas $\left(\mathrm{cm}^{2}\right)$ in the groups. Also, the total surface $\left(\mathrm{cm}^{2}\right)$ comparison between the groups is presented, as well as the fore-foot surface $\left(\mathrm{cm}^{2}\right)$ and rear-foot surface $\left(\mathrm{cm}^{2}\right)$. The total left foot surface and total right foot surface $\left(\mathrm{cm}^{2}\right)$ were dtermined as well. In this case, no significant differences were found between the groups.

Table 3 presents the loads on the plantar areas expressed in percentages, as well as the mean pres-

Table 2. Plantar surface areas $\left(\mathrm{cm}^{2}\right)$ in the sedentary $(\mathrm{S})$ and athlete (A) groups

\begin{tabular}{lccc}
\hline Parameter & $\begin{array}{c}\mathrm{S} \\
(n=98)\end{array}$ & $\begin{array}{c}\mathrm{A} \\
(n=75)\end{array}$ & $p$-value \\
\hline Total surface $\left(\mathrm{cm}^{2}\right)$ & $246.48 \pm 34.14$ & $254.71 \pm 32.21$ & $\mathrm{NS}$ \\
Fore-foot surface $\left(\mathrm{cm}^{2}\right)$ & $138.43 \pm 18.79$ & $144.45 \pm 18.92$ & NS \\
Rear-foot surface $\left(\mathrm{cm}^{2}\right)$ & $108.05 \pm 17.15$ & $110.15 \pm 16.33$ & NS \\
Total left foot surface $\left(\mathrm{cm}^{2}\right)$ & $121.68 \pm 17.92$ & $126.44 \pm 18.20$ & NS \\
Total right foot surface $\left(\mathrm{cm}^{2}\right)$ & $124.80 \pm 18.08$ & $128.27 \pm 18.05$ & NS \\
\hline
\end{tabular}

NS - not significant

Table 3. Percentage loads on the plantar areas, maximum peak pressure, and mean pressure values in the sedentary (S) and athlete (A) groups

\begin{tabular}{lccc}
\hline Parameter & $\begin{array}{c}\mathrm{S} \\
(n=98)\end{array}$ & $\begin{array}{c}\mathrm{A} \\
(n=75)\end{array}$ & $p$-value \\
\hline Maximum peak pressure $\left(\mathrm{g} / \mathrm{cm}^{2}\right)$ & $518.06 \pm 111.50$ & $445.38 \pm 88.47$ & 0.0001 \\
Pressure mean $\left(\mathrm{g} / \mathrm{cm}^{2}\right)$ & $232.99 \pm 43.26$ & $217.95 \pm 38.11$ & 0.0182 \\
Fore-foot load $(\%)$ & $50.39 \pm 3.60$ & $52.36 \pm 3.76$ & 0.0006 \\
Rear-foot load $(\%)$ & $49.61 \pm 3.60$ & $47.64 \pm 3.73$ & 0.0006 \\
Total left foot load (\%) & $50.68 \pm 4.27$ & $49.93 \pm 2.97$ & $\mathrm{NS}$ \\
Total right foot load $(\%)$ & $49.32 \pm 4.27$ & $50.07 \pm 2.97$ & $\mathrm{NS}$ \\
\hline
\end{tabular}

NS - not significant 


\section{HUMAN MOVEMENT}

K. Feka et al., How do sports affect static baropodometry?

\section{Baropodometry \\ Plantar load values (Athletes, $N^{\circ} 75$ )}
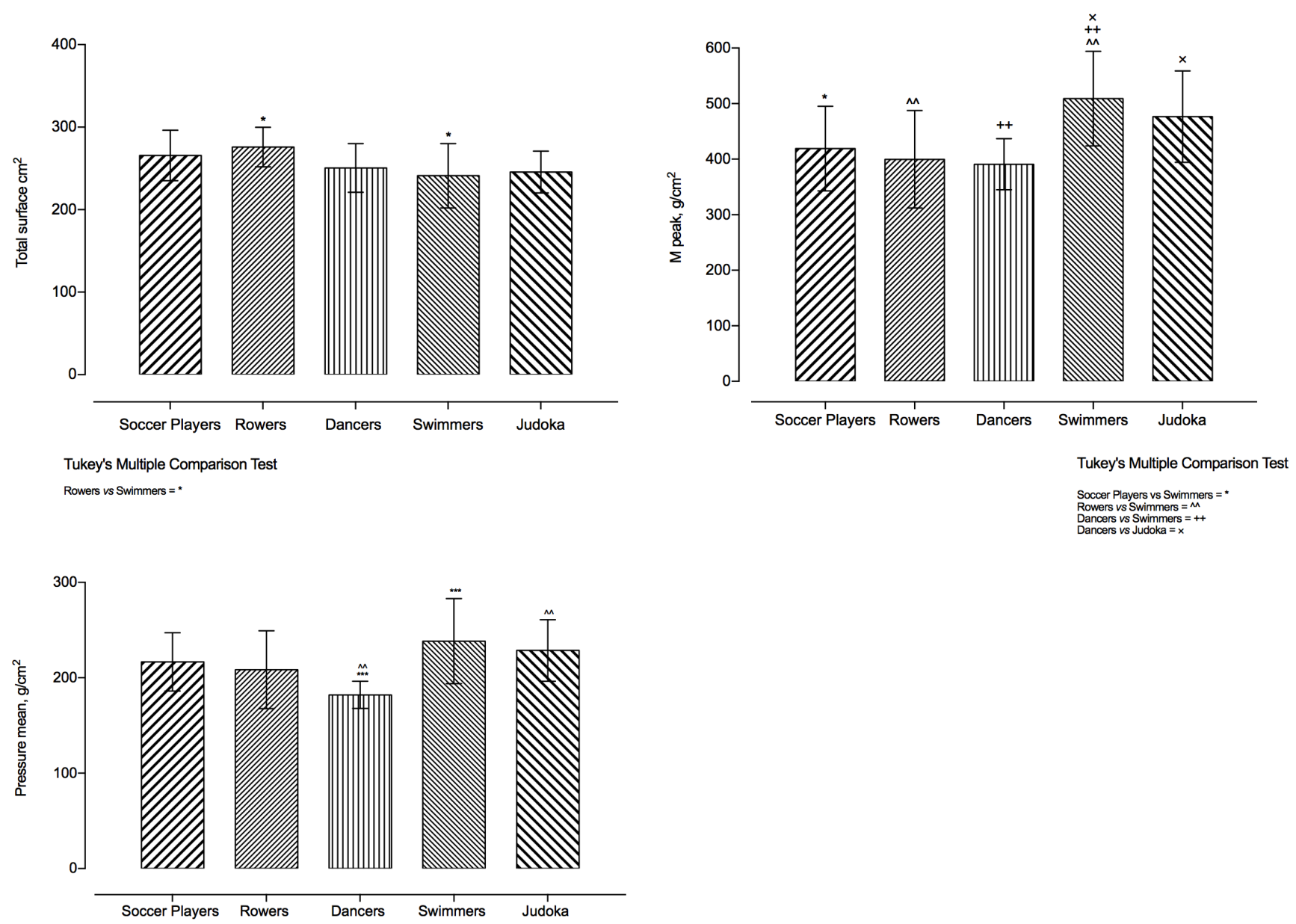

Tukey's Multiple Comparison Test

Dancers us Swimmers $=*+*$
Dancers vs Judoka $=M$

$\mathrm{M}$ peak - maximum peak pressure

Figure 1. Plantar load values in the athletes group (A)

Table 4. Plantar surface values (mean \pm standard deviation) in athlete subgroups

\begin{tabular}{lcccccc}
\hline Parameter & $\begin{array}{c}\text { Soccer players } \\
(n=18)\end{array}$ & $\begin{array}{c}\text { Rowers } \\
(n=11)\end{array}$ & $\begin{array}{c}\text { Dancers } \\
(n=12)\end{array}$ & $\begin{array}{c}\text { Swimmers } \\
(n=16)\end{array}$ & $\begin{array}{c}\text { Judokas } \\
(n=18)\end{array}$ & $\begin{array}{c}p \text {-value } \\
\text { ANOVA }\end{array}$ \\
\hline $\begin{array}{l}\text { Total surface }\left(\mathrm{cm}^{2}\right) \\
265.83 \pm 30.58\end{array}$ & $275.82 \pm 23.95$ & $250.58 \pm 29.37$ & $241.06 \pm 39.00$ & $245.56 \pm 25.44$ & 0.0183 \\
$\begin{array}{l}\text { Fore-foot surface } \\
\left(\mathrm{cm}^{2}\right)\end{array}$ & $155.17 \pm 19.17$ & $152.27 \pm 14.48$ & $139.67 \pm 15.93$ & $136.88 \pm 22.34$ & $139.33 \pm 14.26$ & 0.0474 \\
$\begin{array}{l}\text { Rear-foot surface } \\
\left(\mathrm{cm}^{2}\right)\end{array}$ & $110.67 \pm 14.08$ & $123.55 \pm 11.18$ & $110.92 \pm 15.61$ & $104.19 \pm 20.58$ & $106.22 \pm 13.71$ & 0.0262 \\
$\begin{array}{l}\text { Total left foot } \\
\text { surface }\left(\mathrm{cm}^{2}\right)\end{array}$ & $134.33 \pm 17.54$ & $137.00 \pm 13.18$ & $124.25 \pm 16.50$ & $119.13 \pm 22.18$ & $120.06 \pm 13.63$ & 0.0132 \\
$\begin{array}{l}\text { Total right foot } \\
\text { surface }\left(\mathrm{cm}^{2}\right)\end{array}$ & $131.50 \pm 14.42$ & $138.82 \pm 11.62$ & $126.33 \pm 13.69$ & $121.94 \pm 17.86$ & $125.50 \pm 12.83$ & 0.0378 \\
\hline
\end{tabular}

ANOVA - analysis of variance 
Table 5. Percentage and absolute plantar load values (mean \pm standard deviation) in athlete subgroups

\begin{tabular}{|c|c|c|c|c|c|c|}
\hline Parameter & $\begin{array}{l}\text { Soccer players } \\
\quad(n=18)\end{array}$ & $\begin{array}{l}\text { Rowers } \\
(n=11)\end{array}$ & $\begin{array}{l}\text { Dancers } \\
(n=12)\end{array}$ & $\begin{array}{l}\text { Swimmers } \\
\qquad(n=16)\end{array}$ & $\begin{array}{c}\text { Judokas } \\
(n=18)\end{array}$ & $p$-value \\
\hline $\begin{array}{l}\text { Maximum peak } \\
\text { pressure }\left(\mathrm{g} / \mathrm{cm}^{2}\right)\end{array}$ & $419.00 \pm 76.15$ & $399.45 \pm 87.72$ & $390.82 \pm 46.03$ & $509.00 \pm 85.20$ & $476.61 \pm 82.23$ & 0.0002 \\
\hline $\begin{array}{l}\text { Pressure mean } \\
\left(\mathrm{g} / \mathrm{cm}^{2}\right)\end{array}$ & $216.72 \pm 30.56$ & $208.45 \pm 40.84$ & $182.09 \pm 14.21$ & $238.44 \pm 44.61$ & $228.67 \pm 32.24$ & 0.0008 \\
\hline $\begin{array}{l}\text { Total left foot load } \\
(\%)\end{array}$ & $50.67 \pm 2.57$ & $49.18 \pm 1.17$ & $50.50 \pm 2.58$ & $49.56 \pm 4.38$ & $49.61 \pm 2.91$ & NS \\
\hline$(\mathrm{kg})$ & $29.89 \pm 4.66$ & $28.30 \pm 4.28$ & $23.73 \pm 2.40$ & $27.79 \pm 2.73$ & $27.65 \pm 3.14$ & 0.0007 \\
\hline $\begin{array}{l}\text { Total right foot load } \\
(\%)\end{array}$ & $49.33 \pm 2.57$ & $50.82 \pm 1.17$ & $49.50 \pm 2.58$ & $50.44 \pm 4.38$ & $50.39 \pm 2.91$ & NS \\
\hline (kg) & $29.02 \pm 4.03$ & $29.25 \pm 4.42$ & $23.19 \pm 1.49$ & $28.52 \pm 4.57$ & $28.16 \pm 3.82$ & 0.0010 \\
\hline
\end{tabular}

NS - not significant

sure and maximum peak pressure values in the 2 groups. As shown in the table, there were significant differences in these parameters except the total left foot load (\%) and total right foot load (\%). However, athletes had a higher fore-foot load percentage than the sedentary group ( $p=0.0006)$ and, consequently, a lower rear-foot load percentage ( $p=0.0006)$, as well as lower values of the maximum peak pressure and pressure mean ( $p=0.0001$ and $p=0.0182$, respectively).

Table 4 provides the plantar surface values (mean \pm SD) for athlete subgroups, which were analysed with one-way ANOVA; in all parameters, significant differences were recorded. In fact, soccer players and rowers had the highest plantar surface values, considering the total plantar support, left and right plantar areas, and total fore-foot and rear-foot surfaces $(p<0.05)$, compared with other sports groups (Figure 1).

In Table 5, percentage and absolute plantar load values (mean $\pm \mathrm{SD}$ ) in athlete subgroups are presented. Indeed, a stratification of parameters was found showing different loads on the plantar support among the sport-related subgroups.

Also in this case, significant differences among means were detected with the one way ANOVA. Posthoc results are illustrated in Figure 1.

\section{Discussion}

The aim of the present study was to investigate the differences in plantar pressure distribution between athletes and sedentary women, considering all the collected information regarding plantar pressure distribution and sports specifics.

The characteristics of different sports and physical activities may significantly affect static human bal- ance and posture [26]; for this reason, we decided to perform an observational study to explore the differences, if any, between these parameters in the 2 study groups, as well as between the sports within the athletes group. Moreover, in our data regarding age, height, weight, BMI, BSA, and shoe number, no significant differences were observed. In the comparison of the athletes with sedentary women, the main findings showed no significant differences in total plantar pressure surface, total left or right foot surface, fore-foot or rear-foot surface between these groups. Interestingly, differences were observed in the fore-/rear-foot and left/right load distribution parameters between the athletes and sedentary women, and also within the group of athletes. Our results remain in line with others findings [5, 27-29]. We may hypothesize that athletes tend to lean forward or use fore-foot rather than rear-foot surface owing to the specifics of their sports. As mentioned before, several authors reported the same results when they compared athletes practising different sports, athletes practising the same sport, sedentary people, and people with different health problems [2, 5, 16, 29-36]. In our observations, sedentary participants showed more pressure in the fore-foot than in the rear-foot surface $(50.39 \%$ and $49.61 \%$, respectively). In fact, our findings do not agree with the ideal load values reported by Tribastone and Tribastone [37] and Magee [38], who suggested that $60 \%$ of the weight should rest on the heel and $40 \%$ on the anterior region of the foot.

However, our data are in line with a report by Rosário [1], who stated that there was an higher percentage in plantar pressure in the fore-foot surface. In accordance with the study aim, we also observed differences within the athletes group. Our data show that all ath- 
letes, regardless the practised sport, tend to lean forward, using more fore-foot than rear-foot rest. These results are in agreement with other findings, whose authors state that this phenomenon is due to the athletes' training and the specificity of the practised sport $[2,5,13,29]$.

According to Prochazkova et al. [5], dancers show greater balance ability as compared with other sports participants. In their research, there were significant differences in plantar pressure distribution between dancers and athletes practising other sports, such as football, basketball, running, and fitness. In the current study, dancers tended to use the fore-foot rather than rear-foot surface owing to the specificity of the sport $\left(139.67 \mathrm{~cm}^{2}\right.$ and $110.92 \mathrm{~cm}^{2}$, respectively). Furthermore, these findings show that long-term and intensive dance practice influences the dancers' gait stereotype [5]. According to other authors, after dancers, soccer players present considerable balance ability, compared with other sports [5, 39]. In addition, it has been already discovered that plantar pressure distribution in soccer players is more significant in the forefoot region [13]. In fact, owing to their sport specifics, plantar pressure in soccer players is higher in the preferred foot than in the non-preferred foot, while according to literature, the preferred foot plays a more important role than the non-preferred one in forwarding motions, and the non-preferred foot ensures strong impact with the ground for stability [13]. Our results regarding soccer are in complete agreement with this information. Furthermore, significant differences were found in all parameters that were calculated (total surface, fore-foot surface and rear-foot surface, as well as total left and right surface). Soccer players tend to use fore-foot more than rear-foot [13]. Swimmers usually do not practise or perform static or dynamic balance; however, taking into consideration the specifics of the sport, swimmers also tend to use more fore-foot than rear-foot [2]. This fact has been confirmed in the present study, in which the fore-foot and rear-foot surface turned out to be $136.88 \mathrm{~cm}^{2}$ and $104.19 \mathrm{~cm}^{2}$, respectively. Even rowers have shown that they use more fore-foot $\left(152.27 \mathrm{~cm}^{2}\right)$ than rear-foot $\left(123.55 \mathrm{~cm}^{2}\right)$. These data are in agreement with results reported by Vieira et al. [40]. However, it should be highlighted that the literature regarding the use of baropodometry in rowers is scarce. Furthermore, also judokas, as other sports participants discussed previously, have shown the tendency to use more fore-foot $\left(139.33 \mathrm{~cm}^{2}\right)$ compared with rear-foot $\left(106.22 \mathrm{~cm}^{2}\right)$. The forward head posture of judokas has already been reported in the literature [41].
In all sports, there is a significant difference in total surface, fore-foot and rear-foot surface, as well as total left and right foot surface.

Even though posture may change as a result of exercises, according to Baumfeld et al. [10], plantar pressure distribution does not change in normal participants, no matter how hard their daily activity may be; authors showed no adaptations to a short-term exposure to exercise.

One of the possible study limitations can be the fact that the sample size was small and the baropodometric data must be normalized by shoe number and other variables considered as gold standards in this case. This bias does not allow us to generalize, but interestingly, we discovered that sports practice may affect plantar surface and load distribution also in women.

\section{Conclusions}

The study demonstrated that there were no significant differences in plantar surface areas between the athlete and sedentary groups. Furthermore, the evaluation of the plantar pressure distribution showed a tendency to lean forward in the athletes group when compared with the sedentary group. In addition, the analysis performed among the athletes revealed significant differences between sports. The phenomenon of leaning forward could be due to sports-specific adaptations.

\section{Acknowledgments}

We are grateful to all participants enrolled in the study. Our special thanks go to all members of staff and nurses of the MEDEOR Clinic (Palermo, Italy).

\section{Disclosure statement}

No author has any financial interest or received any financial benefit from this research.

\section{Conflict of interest}

The authors state no conflict of interest.

\section{References}

1. Rosário JL. A review of the utilization of baropodometry in postural assessment. J Bodyw Mov Ther. 2014; 18(2):215-219; doi: 10.1016/j.jbmt.2013.05.016.

2. Hrysomallis C. Balance ability and athletic performance. Sports Med.2011;41(3):221-232; doi: 10.2165/11538560 -000000000-00000.

3. Neto HP, Grecco LA, Braun Ferreira LA, Christovão TC, Duarte Nde A, Oliveira CS. Clinical analysis and baropodometric evaluation in diagnosis of abnormal foot 
posture: a clinical trial. J Bodyw Mov Ther. 2015;19(3): 429-433; doi: 10.1016/j.jbmt.2014.09.007.

4. Takakusaki K. Functional neuroanatomy for posture and gait control. J Mov Disord. 2017;10(1):1-17; doi: 10.14802/jmd.16062.

5. Prochazkova M, Tepla L, Svoboda Z, Janura M, Cieslarová M. Analysis of foot load during ballet dancers' gait. Acta Bioeng Biomech. 2014;16(2):41-45; doi: 10.5277/ abb140205.

6. Kilroy EA, Crabtree OM, Crosby B, Parker A, Barfield WR. The effect of single-leg stance on dancer and control group static balance. Int J Exerc Sci. 2016;9(2):110120.

7. Giacomozzi C, Leardini A, Caravaggi P. Correlates between kinematics and baropodometric measurements for an integrated in-vivo assessment of the segmental foot function in gait. J Biomech. 2014;47(11):26542659; doi: 10.1016/j.jbiomech.2014.05.014.

8. Peltenburg AL, Erich WB, Bernink MJ, Zonderland ML, Huisveld IA. Biological maturation, body composition, and growth of female gymnasts and control groups of schoolgirls and girl swimmers, aged 8 to 14 years: a cross-sectional survey of 1064 girls. Int J Sports Med. 1984;5(1):36-42; doi: 10.1055/s-2008-1025878.

9. Klentrou P, Plyley M. Onset of puberty, menstrual frequency, and body fat in elite rhythmic gymnasts compared with normal controls. Br J Sports Med. 2003; 37(6):490-494; doi: 10.1136/bjsm.37.6.490.

10. Baumfeld D, Baumfeld T, Lopes da Rocha R, Macedo B, Raduan F, Zambelli R, et al. Reliability of baropodometry on the evaluation of plantar load distribution: a transversalstudy.BiomedRes Int.2017;2017:5925137; doi: 10.1155/2017/5925137.

11. Alves R, Porfirio Borel W, Palmeira Rossi B, Danza Vicente EJ, Carvalho Chagas PS, Carvalho Felício D. Test-retest reliability of baropodometry in young asyntomatic individuals during semi static and dynamic analysis. Fisioter Mov. 2018;31:e003114; doi: 10.1590/ 1980-5918.031.AO14.

12. Phethean J, Nester C. The influence of body weight, body mass index and gender on plantar pressures: results of a cross-sectional study of healthy children's feet. Gait Posture. 2012;36(2):287-290; doi: 10.1016/j.gaitpost.2012.03.012.

13. Wong PL, Chamari K, Mao DW, Wisløff U, Hong Y. Higher plantar pressure on the medial side in four soccer-related movements. Br J Sports Med. 2007;41(2): 93-100; doi: 10.1136/bjsm.2006.030668.

14. De Paula Lima PO, Camelo PRP, Ferreira VMLM, do Nascimento PJS, Bezerra MA, Almeida GPL, et al. Evaluation of the isokinetic muscle function, postural control and plantar pressure distribution in capoeira players: a cross-sectional study. Muscles Ligaments Tendons J.2017;7(3):498-503; doi:10.11138/mltj/2017.7.3.498.

15. Potdevin FJ, Femery VG, Decatoire A, Bosquet L, Coello Y, Moretto P. Using effect size to quantify plantar pressure asymmetry of gait of nondisabled adults and patients with hemiparesis. J Rehabil Res Dev. 2007; 44(3):347-354; doi: 10.1682/JRRD.2006.07.0077.

16. Kaercher CW, Genro VK, Souza CA, Alfonsin M, Berton G, Filho JS. Baropodometry on women suffering from chronic pelvic pain - a cross-sectional study. BMC Womens Health. 2011;11:51; doi: 10.1186/1472-6874-11-51.

17. Gravante C, Ruso G, Pomara F, Rubino G, Ridola C, Amato G. Influence of physical activity on plantar pressures and on ground projection of the body barycentre [in Italian]. Med dello Sport. 2002;55(4):269-278.

18. Russo G, Truglio G, Gravante G, Benigno A, Pomara F, Angelomè $\mathrm{C}$, et al. Static and dynamic baropodometric analysis in runners and body-builders [in Italian]. Med dello Sport. 1998;51(3):299-305.

19. Russo G, Gravante G, Amato G, Genduso D, Amato C, Pomara F. Analysis of plantar support and pressure centre in adolescents: a comparison between athletes and sedentary people [in Italian]. Chirurgia Del Piede. 2003;27(1):19-24.

20. Tománková K, Přidalová M, Svoboda Z, Cuberek R. Evaluation of plantar pressure distribution in relationship to body mass index in Czech women during walking. J Am Podiatr Med Assoc. 2017;107(3):208214; doi: 10.7547/15-143.

21. Sims EL, Hardaker WM, Queen RM. Gender differences in plantar loading during three soccer-specific tasks. Br J Sports Med. 2008;42(4):272-277; doi: 10.1136/bjsm.2007.042432.

22. Messina G. The tongue, mandible, hyoid system. Eur J Transl Myol. 2017;27(1):74-76; doi: 10.4081/ejtm.2017. 6363.

23. Petry VKN, Paletta JRJ, El-Zayat BF, Efe T, Michel NSD, Skwara A. Influence of a training session on postural stability and foot loading patterns in soccer players. Orthop Rev. 2016;8(1):6360; doi: 10.4081/or.2016.6360.

24. Mosteller RD. Simplified calculation of body-surface area. N Engl J Med. 1987; 317:1098; doi:10.1056/ NEJM198710223171717.

25. Khasnis A, Gokula RM. Romberg's test. J Postgrad Med. 2003;49(2):169-172.

26. Paillard T, Montoya R, Dupui P. Postural adaptations specific to preferred throwing techniques practiced by competition-level judoists. J Electromyogr Kinesiol. 2007;17(2):241-244; doi: 10.1016/j.jelekin.2006.01.006.

27. Paillard T, Costes-Salon C, Lafont C, Dupui P. Are there differences in postural regulation according to the level of competition in judoists? Br J Sports Med. 2002;36(4): 304-305; doi: 10.1136/bjsm.36.4.304.

28. Pauk J, Ihnatouski M, Najafi B. Assessing plantar pressure distribution in children with flatfoot arch: application of the Clarke angle. J Am Podiatr Med Assoc. 2014;104(6):622-632; doi: 10.7547/8750-7315-104.6.622.

29. Gobbi G, Galli D, Carubbi C, Pelosi A, Lillia M, Gatti R, et al. Assessment of body plantar pressure in elite athletes: an observational study. Sport Sci Health. 2013; 9(1):13-18; doi: 10.1007/s11332-013-0139-8. 


\section{HUMAN MOVEMENT}

K. Feka et al., How do sports affect static baropodometry?

30. Anjos DMC, Gomes LPO, Sampaio LMM, Correa JCF, Oliveira CS. Assessment of plantar pressure and balance in patients with diabetes. Arch Med Sci. 2010; 6(1):43-48; doi: 10.5114/aoms.2010.13506.

31. Notarnicola A, Maccagnano G, Fiore A, Spinarelli A, Montenegro L, Paoloni M, et al. Baropodometry on patients after total knee arthroplasty. Musculoskelet Surg. 2018;102(2):129-137; doi: 10.1007/s12306-017-0505-9.

32. Matsuda S, Fukubayashi T, Hirose N. Characteristics of the foot static alignment and the plantar pressure associated with fifth metatarsal stress fracture history in male soccer players: a case-control study. Sports Med Open. 2017;3(1):27; doi: 10.1186/s40798-017-0095-y.

33. Teymouri M, Halabchi F, Mirshahi M, Mansournia MA, Mousavi Ahranjani A, Sadeghi A. Comparison of plantar pressure distribution between three different shoes and three common movements in futsal. PLoS One. 2017;12(10):e0187359; doi: 10.1371/journal.pone. 0187359.

34. Castillo-López JM, Vargas-Macías A, Domínguez-Maldonado G, Lafuente-Sotillos G, Ramos-Ortega J, Palomo-Toucedo IC, et al. Metatarsal pain and plantar hyperkeratosis in the forefeet of female professional flamenco dancers. Med Probl Perform Art. 2014;29(4): 193-197.

35. Hills AP, Hennig EM, McDonald M, Bar-Or O. Plantar pressure differences between obese and non-obese adults: a biomechanical analysis. Int J Obes Relat Metab Disord. 2001;25(11):1674-1679; doi: 10.1038/sj.ijo. 0801785.

36. Gravante G, Russo G, Pomara F, Ridola C. Comparison of ground reaction forces between obese and control young adults during quiet standing on a baropodometric platform. Clin Biomech. 2003;18(8):780-782; doi: 10.1016/S0268-0033(03)00123-2.

37. Tribastone F, Tribastone P. Compendium of preventive and compensatory motor education [in Italian]. Roma: Società Stampa Sportiva; 2001.

38. Magee DJ. Musculoskeletal evaluation [in Portuguese]. $4^{\text {th }}$ ed. São Paulo: Editora Manole; 2005.

39. Gerbino PG, Griffin ED, Zurakowski D. Comparison of standing balance between female collegiate dancers and soccer players. Gait Posture. 2007;26(4):501-507; doi: 10.1016/j.gaitpost.2006.11.205.

40. Vieira T, Botter A, Gastaldi L, Sacco ICN, Martelli F, Giacomozzi C. Textured insoles affect the plantar pressure distribution while elite rowers perform on an indoorrowingmachine.PLoSOne.2017;12(11):e0187202; doi: 10.1371/journal.pone.0187202.

41. Castropil W, Arnoni C. Postural patterns and adaptations in judo athletes. Archives of Budo. 2014;10:23-28. 